and properly belongs with religion where it is practised, while at the same time all-important 'wisdom' is developed. This is what one is blindly 'measuring' in well seasoned monks.

95 Fairacres Road, Cílve Sherlock

Oxford OX4 1TQ

\section{MENSTRUATION, MOOD AND MENTAL HANDICAP}

Dear Sir,

It is widely reported that the female menstrual cycle polarises certain events in women's lives so that they occur much more frequently in the paramenstruum (premenstrually and with menstruation). Katharina Dalton (1977) reports that schoolgirls' examination results, schoolgirls' offences, offences by women prisoners, accident proneness, admission to both general and psychiatric hospitals and suicide attempts occur more frequently in the paramenstruum than at other times of the cycle. Birtchnell and Floyd (1974) do not find a relationship between attempted suicide and the menstrual cycle and point out many of the statistical problems in relating events to menstruation, as the menstrual cycle is not itself a regular predictable event.

This is a report of a pilot study to assess the effect of menstruation on the behaviour and mood of female patients with mental handicap. Women with mental handicap were selected, as it was felt that they would be less able to conceal mood changes, and that the mood changes would be reflected in behavioural changes. Preliminary discussion of the study with medical and nursing staff suggested that we would find a clear cut relationship between behaviour and menstruation. A questionnaire was devised with five questions

(1) Has the patient shown any abnormal elation or depression today?

(2) Has the patient had an episode in the last 24 hours of shouting, being destructive, excessive overactivity, interfering or aggression?

(3) Has the patient been unusually either under- or overactive?

(4) Has the patient either complained of or indicated that she has abdominal (period) pain?

(5) Has the patient been more dependent upon nursing staff or more attention-seeking than usual?

These were scored on a 4-point scale-No; Just noticeable-Slight; Moderate; Very Marked. For 84 consecutive days all menstruating patients in a 60 bedded mental handicap hospital were studied. The questionnaires were completed every day, and a separate record was kept of menstruation, epilepsy and medication.
There were 60 patients in the hospital, and records were completed for 29 ( 48 per cent) of patients, although only 25 (42 per cent) menstruated during the three months of the study. Fifty-two menstrual cycles were recorded in 25 women. In 16 women no change in mood or behaviour was recorded at any time. In nine women there were changes in mood and behaviour, but in only two of these nine did changes occur in the paramenstruum. In one of these patients three menses were recorded but here mood and behaviour changed in the paramenstruum of only one mensis. The other patient had two menses recorded, she had paramenstrual symptoms with one mensis but none with the other, and she also had behavioural changes which were unrelated to menstruation.

So out of 52 menstrual cycles recorded, in only two were there noticeable changes in mood and behaviour in relation to menstruation. These findings are at variance with the results predicted by nursing and medical staff, and imply that the menstrual cycle is not an important variable in the control of mood and behaviour in female patients with mental handicap.

This was a pilot study and it might be valuable to assess a larger group of patients with mental handicap, including those living in hostels and the community.

Middlewood Hospital,

G. A. SAmpson

Sheffield S6 1 TP

\section{References}

Dalton, K. (1977) The Premenstrual Syndrome and Progesterone Therapy. Chapter 19. London: W. Heinman Medical Books.

Birtchinel, J. \& Floyd, S. (1974) Attempted suicide and the menstrual cycle-a negative conclusion. Fournal of Psychosomatic Research, 18, 361-9.

\section{SCHOOL PHOBIC CHILDREN AT WORK}

Dear Sir,

The final sentence of the article by Baker and Wills (Journal, December 1979, 135, 561-64) and its summary is a non-sequitur to all the preceding article. The authors present no evidence that there are any 'underlying conditions' to school phobia, nor that adequate treatment of these supposed conditions is beneficial, let alone being 'more important than returning the child to school'. In fact, the cynic might conclude that such treatment might indeed be counterproductive in view of their finding that significantly more children who received further psychiatric treatment after discharge later failed to reach their potential in work or further education. Of 
course the more probable explanation of the latter is that the more disturbed patients had longer treatment because they remained disturbed at discharge.

As only 10 of the cases were off school for over a year, and many may have been towards the end of their normal schooling careers anyway, seeing that cases were included up to age 16 , not much can be concluded from the data presented. The sweeping conclusion that prolonged time away from school has no long-term effect would need far more carefully gathered data than those presented.

Institute of Psychiatry,

ISAAC MARKS

De Crespigny Park,

London SE5 8AF

DeAR SiR,

We are gratified that such a distinguished adult psychiatrist has taken an interest in our paper and we welcome his comments.

The 'underlying conditions' are listed in Table II. In 57 of our 67 children there was a psychiatric diagnosis apart from phobia of school per se. These conditions needed more than purely behavioural therapy, and we continued treatment where necessary after the child had returned to school. Fourteen cases relapsed some time after completion of treatment and discharge and needed further treatment, but 11 of these 14 children had returned to school. The need for further treatment was not related to return to school.

. In the group off school over a year 3 were over 14 , and in the group off 7-12 months 3 were over 14. The solitary 16 year old was off school under 6 months and returned to school.

Details of the extensive data we collected on these children are available on request.

Rockville,

HAZEL B. BAKER

Oakhurst,

Lichfield, Staffs DeAr Sir,

TRANYLCYPROMINE ADDICTION

In 'A Case of Tranylcypromine ('Parnate') Addiction' (Journal, September 1979, 135, 273-4), Ben-Arie and George pointed out that even though the supposed 'addict' had previously abused barbiturates and alcohol 'when depressed', there was 'no history of alcohol or other drug abuse during the period on tranylcypromine'. However, these investigators should realise that the patient's drug abuse just prior to being placed on tranylcypromine therapy could have kept his hepatic microsomal enzyme system in a stimulated state. Indeed, it might have taken several weeks before a normal, slower metabolizing rate could be restored (Conney, 1967). As this system metabolizes tranylcypromine, the need to rapidly increase the daily dose of this drug to relieve depression may not be due to an 'addiction', but just increased metabolic demands.

The possibility of autoinduction of metabolizing enzymes by tranylcypromine should not be ruled out either. This has been observed with several other drugs used in psychiatric practice, including chlorpromazine (Rivera-Calimlim et al, 1979) and phenobarbitone (Prescott, 1978). Autoinduction may result in faster metabolism and hence increasing dosage requirements of tranylcypromine.

Gary E. Pakes

Drug Information Services,

15 Rawene Road,

Birkenhead PO Box 34-030,

Auckland 10, New Zealand

\section{References}

Conney, A. H. (1967) Pharmacological implications of microsomal enzyme induction-a critical reappraisal. Pharmacological Reviews, 19, 317-66.

Prescotr, L. F. (1978) Clinically important drug interactions. In Drug Treatment (ed. G. S. Avery). Sydney, Australia: ADIS Press.

Rivera-Calimlim, L., Griesbach, P. H. \& Perluutter, R. (1979) Plasma chlorpromazine concentrations in children with behavioral disorders and mental illness. Clinical Pharmacology and Therapeutics, 26, 114-21.

\section{OVERDOSE-TAKERS AND SELF-MUTILATORS}

Dear Sir,

It is widely accepted that deliberate overdosetakers and self-mutilators have many characteristics in common. For example, they are usually young, adult and female (Smith and Davison, 1971; Roy, 1978). Many ingest alcohol prior to self-injury (Ellis et al, 1966; Simpson, 1975). In most cases the selfinjury was impulsive (Smith, 1972; Simpson, 1976), and many such patients have a personality disorder.

We report on 130 patients, 100 overdose-takers and 30 self-mutilators (by laceration). They were all consecutive referrals from the wards and casualty departments of two general hospitals in Newcastle upon Tyne. A standard history was completed on each patient, the data were analysed by chi-squared test and where the numbers were small Fisher's Exact Probability Test was used.

On the following items the two groups did not significantly differ:-sex, age, employment status, marital status, time when self-injury occurred, 